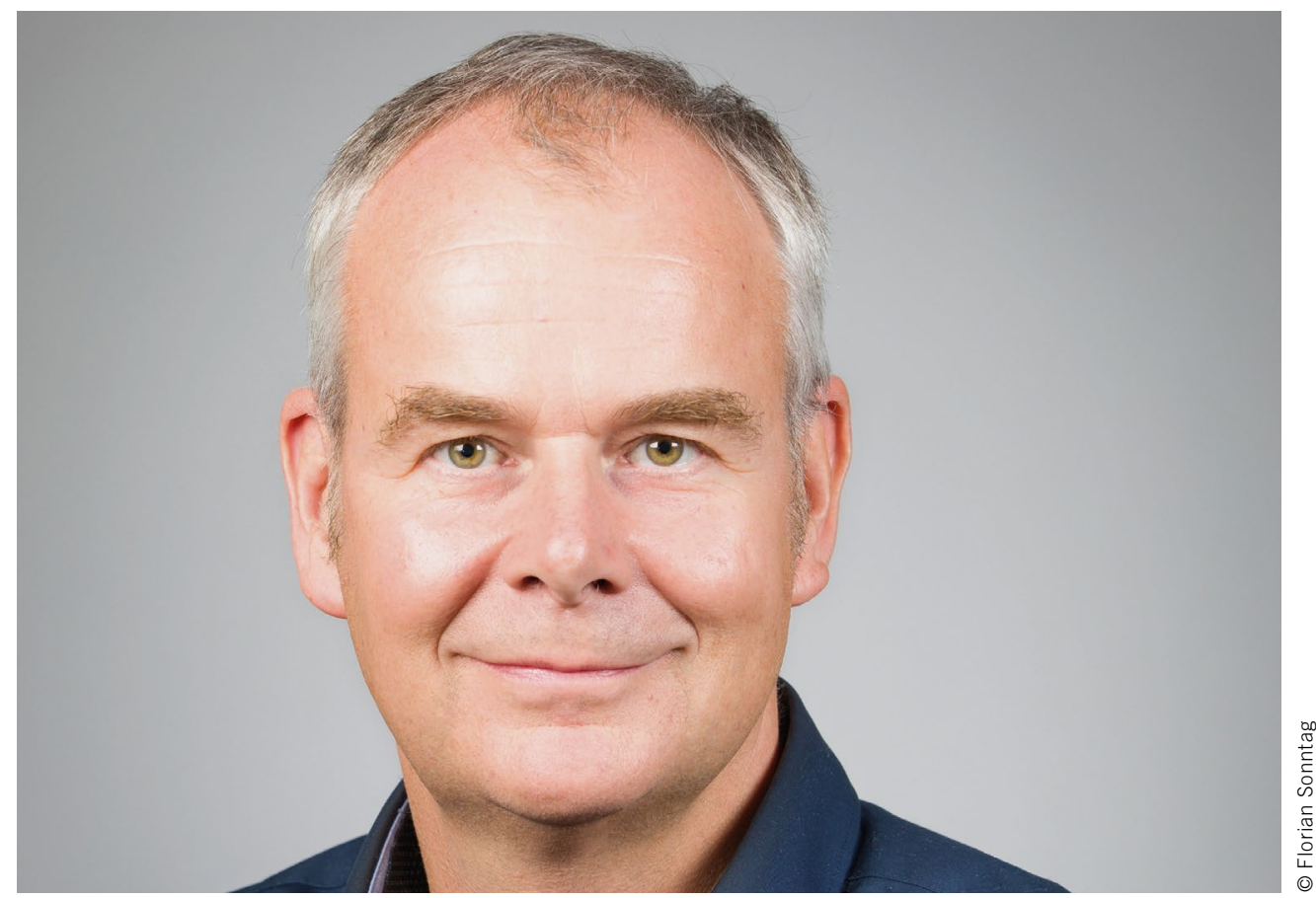

Dr.-Ing. Karsten Wilbrand

Senior Principal Scientist bei Shell

\title{
Wir brauchen Technologieoffenheit
}

Die Energiewende erfordert einen weitgehenden Umbau unseres heutigen, auf fossilen Energieträgern basierenden Systems hin zu einem, das erneuerbare Energien nutzt. Alle Sektoren müssen einen Beitrag dazu leisten. Die Elektrifizierung des Verkehrssektors steht zwar im Vordergrund, doch Technologieoffenheit ist gefragt.

Auch in den Sektoren Industrie und Gebäude gibt es einen klaren Trend zur Elektrifizierung. Eine Verdoppelung des europäischen Strombedarfs bis 2050 scheint daher nicht unrealistisch. Selbst wenn es gelingt, die Erzeugung von erneuerbarem Strom in Europa erheblich zu steigern, bleibt die Frage, wie zukünftig die fluktuierenden erneuerbaren Energien durch erneuerbare Grundlasterzeugung, verbesserte Netzintegration und Speicherung abgesichert werden können.

Zur Grundlasterzeugung setzt die neue deutsche Bundesregierung auf die Errichtung moderner Gaskraftwerke, die auf klimaneutrale Gase $\left(\mathrm{H}_{2}\right.$-ready) umgestellt werden können. Sie misst Wasserstoff für die Energiewende eine überragende Bedeutung zu. Deutschland soll Leitmarkt für Wasserstofftechnologie werden; die heimische Elektrolysekapazität soll bis 2030 auf $10 \mathrm{GW}$ wachsen. Die EU hat im Dezember ein Paket zur Dekarbonisierung der Gaswirtschaft vorgestellt, in dem Wasserstoff ebenfalls eine wesentliche Rolle spielt.

Neben einheimischer Erzeugung bietet sich die $\mathrm{H}_{2}$-Produktion insbesondere dort an, wo sie möglichst kostengünstig, nachhaltig und bei guter Flächenverfügbarkeit erfolgen kann.
Regionen wie Nordafrika, der Nahe/Mittlere Osten, Patagonien oder Australien sind prädestiniert. Je nach Transportentfernung und Endanwendung kann der Import via Pipeline oder per Schiff als Flüssigwasserstoff oder synthetisch hergestellte Wasserstoff-Derivate wie Methanol, Ammoniak oder E-Fuels erfolgen.

Wenn in Zukunft sowohl lokal produzierter als auch importierter Wasserstoff rückverstromt werden muss, dann relativiert sich die Diskussion um den besseren Well-to-Wheel-Wirkungsgrad des BEV-Lkw (60\% im Vecto-Zyklus) gegenüber einem Wasserstoff-Lkw (24\%). Denn ein BEV-Lkw, der zu 50 \% mit direkt erzeugtem Strom und zu $50 \%$ aus $\mathrm{H}_{2}$-Rückverstromung geladen wird, kommt auf einen WtW-Wirkungsgrad von knapp $32 \%$. Noch nicht berücksichtigt ist dabei, dass dieselbe PV- oder Windkraftanlage an geeigneten Lokationen deutlich mehr Strom liefert als in Deutschland.

Bei zunehmendem Bedarf an grünen Molekülen für EnergieImport, Speicherung und Rückverstromung ist daher auch der direkte Einsatz dieser Moleküle im Verkehrssektor und damit ein technologieoffener Ansatz sinnvoll. Für den Straßenverkehr kann je nach Anwendungsfall elektrischer Strom oder Wasserstoff die bessere Lösung sein. Für Anwendungen mit sehr hohem Energiebedarf, wie Non-Road, Schifffahrt und Luftverkehr sehe ich neben Biokraftstoffen mittel- und langfristig Wasserstoff und E-Fuels als unverzichtbare Optionen zur Dekarbonisierung. 